\title{
Virtual Dashboard for Assessing Data Centers Green Compliance
}

\author{
Fatemeh Binesh ${ }^{1}$, Saravanan Muthaiyah ${ }^{2}$ \\ ${ }^{1} \mathrm{PhD}$. Student, University Malaya, Malaysia \\ Nasim.binesh@yahoo.com \\ ${ }^{2}$ Assoc. Prof. , Multimedia Unievrsity, Malaysia \\ Saravanan.Muthaiyah@mmu.edu.my
}

\begin{abstract}
Nowadays, ICT sector activities and in particular Data Centers are known as an important environmental hazard. With the increasing popularity of the Internet and cloud computing, this threat seems to even get worse in the near future. Despite this increasing importance, there is still little have been done about data centers environmental affects and in particular measuring their green compliance level including all three Rs of waste management (Reuse, Reuse and Recycle). This paper tries to introduce a dashboard for evaluating data centers' level of green compliance regardless of their tier. However, the dashboard is proposed based on Malaysia's data centers condition, it still can be beneficial to data center managers in other parts of the world and researchers to open up new research possibilities.
\end{abstract}

\section{Indexing terms/Keywords}

Green Data Center, Software Development Life Cycle, Green Metrics, 3Rs

\section{Academic Discipline And Sub-Disciplines}

Magement studies, environmental studies

\section{SUBJECT CLASSIFICATION}

Environemental issues

\section{TYPE (METHOD/APPROACH)}

Interview

\section{Council for Innovative Research}

Peer Review Research Publishing System

\section{Journal: International Journal of Management \& Information Technology}

\author{
Vol. 6, No. 1 \\ editor@cirworld.com \\ www.cirworld.com, member.cirworld.com
}




\section{INTRODUCTION}

In the urging concern towards environmental sustainability, ICT sector plays an important role. In 2010, CO2 emissions from U.S. data centers alone were greater than the whole CO2 emissions from Netherlands or Argentina (Lucente, 2010). In 2004, about 100 million computers were disposed as e-waste, which contained highly toxic materials like mercury (Hilty, 2005). A typical data center's power consumption can reach 3000 times that of a three-bedroom house (Daim et al, 2009).

The number of data centers is forecasted to rise rapidly in the following years due to increasing dependence of industries on IT facilities, rapid growth of the Internet, and the increasing importance of Cloud Computing.

1) Increasing dependence of Industries on IT:

In the world today, managing huge amount of data has become one of the most important aspects in any industry. From online banking E-businesses to government procurement, businesses are looking for outsourcing their data.

2) Rapid growth of the Internet:

The Internet is spreading faster than ever. In North America solely $68.6 \%$ of the population were reported using Internet in the year 2006, which indicates a growth of $110.4 \%$ in less than only 6 years (Yi and Thomas 2007). As a result, the need for 24/7 nonstop Internet and data connection is a vital criterion in the E-world. E-businesses and E-commerce players like online banking need access to massive amount of data daily.

\section{3) Cloud Computing:}

The emergence of could computing concept in the 1960s and its subsequent popularity in the 2000s, is another reason behind the vast growth of data centers in the recent years. Cloud computing is a new way of accessing to your data from anywhere at any time, which uses Internet Data Centers to reserve and manipulate the data. Cloud as a metaphor for Internet, is a rather new definition in the IT industry, however like many other innovation in technology, it already has opened its place into normal people's lives. As an instance apple Inc. introduced iCloud for its PC and other apple gadgets to have access to their data such as music, videos (Apple 2011).

Energy scarcity, carbon emissions, and massive amount of annual electronic waste are a few examples of negative impacts of data centers in the environment.

Nowadays U.S. has the largest number of data centers, while other countries like China and European Union are catching up rapidly due to data centers role in sectors such as finance, media and internet (GeSi, 2008).

As a result, various studies have been done on data centers green compliance, and different organizations have started working on data centers environmental stewardship, such as The Green Grid, EPA and Uptime Institute.

\section{LITERATURE REVIEW}

\subsection{Green Data Center Models \& Tools}

In the recent years various green assessment tools have been provided. However, none of these tools covers all the 3Rs concept aspects.

A brief look at two of the most well known proposed tools is shown below.

\subsubsection{The Green Grid's Data Center Maturity Model}

DCMM is a comprehensive model that allows data center managers to move toward a greener facility. This consists of 5 levels, each less than 1 -year period:

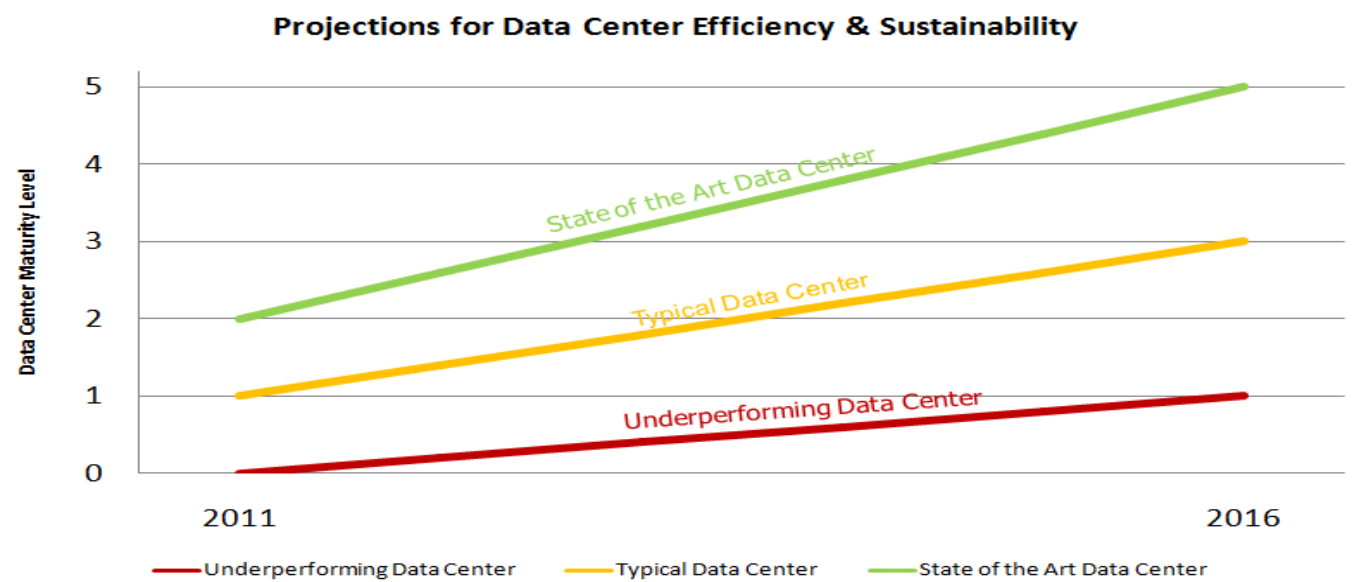

Fig 1. Demonstration of Progress Levels By Using DCMM Source: (The Green Grid 2011) 
Level 0: Start- No progress

Level 1: Part Best Practice

Level 2: Best Practice

Level 3: Improving Initiatives

Level 4: Continuing Improvement

Level 5: Visionary

Each level has initiatives that qualify all means of opening at the next level.

This tool considers different aspects of a data center:

- $\quad$ IT equipment (Network, Compute and Storage)

- Cooling Management

- Power Supply

- E-Waste management including reselling, reusing and recycling

- Water measurement

- Reusing heat

Disadvantages:

- $\quad$ DCMM is not a tool; it consists of policies and procedures to achieve a greener data center. However, does not provide software or tool to ease the monitoring process.

- It is not a standard or certification.

\subsubsection{APC's Data Center Calculators}

Established in 1981, American Power Conversion Corporation (APC) is a manufacturer of UPS and power supply, data center automation and cooling system and power distribution equipment.

Acquired by Schneider Electrics in 2006, APC has offered a collection of free flash tools for managing data centers' power and energy efficiency.

Among more than 12 independent calculators offered by APC, have green assessment criterion such as PUE metric, IT load and carbon emissions.

A brief look is given at four of the green tools involved:

1) Data Center Power-Sizing calculator

This simple tool allows the user to assess the total required DC IT load capacity and utility input power by filling in the detail about IT equipment.

It gives the user the option to manage their own needs of IT equipment based on their type (server, mainframe, storage) as well as the number of them.

\section{2) Data Center Carbon Calculator}

This helpful calculator uses the location of data center, PUE and power load to evaluate its related CO2 emissions. One of the interesting options is the forecast for the $\mathrm{CO} 2$ emissions in 15 years and possible savings and $\mathrm{CO} 2$ emissions during that period.

It also converts the carbon footprint into the equivalent number of cars to make that emission. By choosing location, data center managers can use the currency of their country and the related power costs for each kilowatt.

\section{3) Data Center Efficiency Calculator}

This simple and helpful tool is designed to calculate the annual energy cost and PUE of a given data center. By entering data center power capacity, IT loads, UPS and cooling system characteristics, data center managers can assess their annual PUE.

One of the interesting options in this calculator is offering PUE curve, which allows the user to watch the instant changes in their PUE and energy cost by changing the criteria. Not only changes in the overall energy consumption, but even slight changes in the lighting system and cooling system design are considered, such as floor layout, using CRAC units on UPS system and heat rejection pumps.

4) Cooling economizer mode PUE calculator

This calculator is designed to evaluate the possible savings of money and energy by using free cooling options. By inserting cooling system details, location of data center, power capacity and lighting options, data center managers can compare the PUE, CO2 emissions and energy costs of using or not using economizer mode.

Advantages: 
- Easy to use

- Fast to see the results

- Customization ability to the user based on their needs

- Able to compare two scenarios

Disadvantages:

- Independent tools, no interaction between them

- Focus only on energy efficiency and related carbon footprint

- $\quad$ No reusing, recycling, and water management metrics

\subsubsection{ENERGY STAR Online Portfolio Manager}

This free online tool first was introduced for commercial companies to manage and monitor their energy and water consumption.

By 2008 , more than 62,000 building were already using this tool and among them 4,000 won ENERGY STAR label, which means $35 \%$ less energy consumption than the average for commercial building. From 2012 ENERGY STAR included data centers into the tool.

Using the tool is easy, by inserting the data center space, IT energy, total energy and water use data center managers and owners are able to monitor their building performance, water and energy consumption and compare their facilities with others.

Using the tool starts by registering into the website, which is free. Afterwards, one can create a portfolio of one or more buildings by inserting the acquired data. Inserting data is possible directly at the member's homepage, as well as via filling a pre-designed excel file.

Advantages:

- Free to use: registration on the website and using this tool is completely free.

- Simplicity: working and inserting the data is straightforward.

- Various report options: this tool provides a list of reports and opportunities such as:

- Overall energy and water performance of the data center

- $\quad$ Comparing specific periods' performance

- $\quad$ Rating the overall portfolio's performance in a scale of 1-100

- Opportunity to gain ENERGY STAR label: The building that achieve a rate of $75 \%$ and above, become eligible to apply for ENERGY STAR label, which will attract more customers, investors and implies extra cost savings. (ENERGY STAR 2012).

Disadvantages:

This tool is a very helpful and rather easy to use, however lacks many aspects of data centers' environmental sustainability and specially reusing and reducing metrics.

Also, in terms of reducing energy, this tool doesn't go more in depth into different parts of data center energy usage and simply uses the IT equipment and the overall energy consumption of a given data center.

All of these different tools are offered based on the application areas: hardware, software or cooling system. Thus a comprehensive solution which considers all of the different components in a given data center can be the optimal one, which of course needs future work (Narayan 2009).

Although there is no standardized procedure or metric set available to improve the "green" level of a data center, many experts has recommended benchmarking of the data center energy consumption as the initial move (Tomory 2010).

\section{DEVELOPING THE GREEN DASHBOARD}

Once all the data has been provided and entered into the data entry sheets, the tool automatically does the rest. The final results will be available in the dashboard sheet. For implementation of the concept of this research, System Development Life Cycle (SDLC) was chosen to design and create the 3 color-coding dashboard.

Several approaches have been proposed for SDLC structure, among which the waterfall model as the origin of all the other versions was the most suitable approach for the scope of this study. The reason is that the objective of this research was building the final tool on Microsoft Excel rather than implementing completely new software (PM Solutions 2003). The waterfall model is a cascading approach, in which each stage is dependent on the previous one. It starts by defining the scope of project and ends by using the built tool (Davis, Bersoff and Comer 1988).

In this study, a modified version of the waterfall model was used, due to the fact that the aim of this research was testing the concept of 3 color-coding dashboard by building it in Microsoft Excel Sheets platform, therefore, it did not include maintenance and development section of the regular Waterfall Model and instead ended by testing the dashboard. 


\subsection{Planning \& Analysis}

The first attempt for designing any tool is defining the criteria and goals. To do this, based on the literature review of similar tools were observed and their strengths and weaknesses were recognized. Details of this assessment have provided in Chapter 2, section 2.6.

Afterwards, a list of requirements was taken:

1. Simple and easy to operate.

2. Include 3Rs Metrics: most of the previous tools like APC and ENERGY Star have only focused on reducing aspects of data centers.

3. Fast illustration: it is vital to provide assisting gauges and meters to demonstrate the evaluation of data center in a glance.

In order to pre-design the dashboard, process flow diagram and data flow diagram were used to illustrate the desired process of the final tool.

\subsection{Design}

After knowing what is going to be achieved, it was time to design the tool. The theme for designing the tool was a 3 colorcoding diagnostic dashboard that was programmed on Microsoft Excel spreadsheet. The reason of choosing 3 colorcoding dashboard was the simplicity of using 3 colors, as the basis. Afterwards, the possible development of this tool is an extended 5 color-coding dashboard.

\subsection{Data Entry}

Once the data are obtained from the data center, all the data used in the color-coding dashboard should be inserted by using keyboard. The entry of data is easy and the person in charge would know exactly where to put them, as the tool offers multiple sheets for data from each part of the data center.

The required data for this analysis are:

Table.1 Required Data for Using Dashboard

\begin{tabular}{|ll|}
\hline Data & Unit \\
Overall Energy Consumption of Data Center & $(\mathrm{kWh})$ \\
IT Equipment Energy Consumption & $(\mathrm{kWh})$ \\
UPS input and output power & $(\mathrm{kW})$ \\
Water consumption & $(\mathrm{L})$ \\
Renewable energy & $(\mathrm{kWh})$ \\
Cooling system power consumption & $(\mathrm{kW})$ \\
Cooling system return and supply air temperature & $\left({ }^{\circ} \mathrm{F}\right)$ \\
Relative Humidity of IT Equipment & \\
Fans supply and return power & $(\mathrm{kW})$ \\
Fan Supply and return airflow & $(\mathrm{cfm})$ \\
No. of racks & \\
Racks inlet and outlet temperature & \\
IT equipment intake temperature & \\
Material inbound & $(\mathrm{kg})$ \\
Material Outbound & $(\mathrm{kg})$ \\
Recycled, Reused, Reclaimed Material & $(\mathrm{kg})$ \\
\hline
\end{tabular}

\subsection{Calculation of Green Metric}

After entering the data into relevant sheets, each metric was calculated by using the related formula. In order to be able to use different metrics with different types, all the metrics later were converted to their equivalent percentage. For example, PUE 1.2 was converted to its equivalent percentage by dividing 1 by 1.2 . The procedure for each metric was based on its definition and formula.

The reasons behind choosing percentage for all the metrics were:

1. Percentage allows users to instantly examine the situation, compared to numbers. 
2. Most of the metrics were based on percentage.

\subsection{Color Coding}

By using conditional formatting the coloring of dashboard cells was done, which allows changing the cell's color and font by certain criteria. In this case, the criteria were the cell value. Each criterion was chosen based on the literature review done in chapter 2 . The range and associated color for each metric are shown in the table below

Table.2 Range of Color Coding Criterions For Each Green Metric

\begin{tabular}{|c|c|c|c|}
\hline Metric & Red & Yellow & Green \\
\hline PUE & $0 \%-40 \%$ & $40 \%-67 \%$ & $\geq 67 \%$ \\
\hline UPS Efficiency & $\leq 85 \%$ & $85 \%-90 \%$ & $\geq 90 \%$ \\
\hline CSE & $\leq 16.67 \%$ & $16.67 \%-58.33 \%$ & $\geq 58.33 \%$ \\
\hline WUE & $\leq 33.33 \%$ & $33.33 \%-66.67 \%$ & $\geq 66.67 \%$ \\
\hline CUE & $\leq 33.33 \%$ & $33.33 \%-66.67 \%$ & $\geq 66.67 \%$ \\
\hline $\mathrm{RCl}(\mathrm{Hi})$ & $<90$ & $90 \%-95 \%$ & $\geq 95 \%$ \\
\hline $\mathrm{RCl}(\mathrm{Lo})$ & $<9$ & $90 \%-95 \%$ & $\geq 95 \%$ \\
\hline $\mathrm{RTI}$ & $\leq 75 \%$ or $\geq 125 \%$ & $115 \%-125 \%$ & $85 \%-115 \%$ \\
\hline Airflow Efficiency & $\leq 4$ & $40 \%-70 \%$ & $>70 \%$ \\
\hline Temperature & $<50^{\circ} \mathrm{F}$ or $>90^{\circ} \mathrm{F}$ & $50^{\circ} \mathrm{F}-61^{\circ} \mathrm{F}$ & $61^{\circ} \mathrm{F}-75^{\circ} \mathrm{F}$ \\
\hline Humidity & $20 \%$ or $\geq 80 \%$ & $20 \%-25 \%$ & $25 \%-60 \%$ \\
\hline ERE & $\leq 33.33 \%$ & $33.33 \%-66.67 \%$ & $\geq 66.67 \%$ \\
\hline MRR & $\leq 33.33 \%$ & $33.33 \%-66.67 \%$ & $\geq 66.67 \%$ \\
\hline GEC & $\leq 33.33 \%$ & $33.33 \%-66.67 \%$ & $\geq 66.67 \%$ \\
\hline MRR & $\leq 33.33 \%$ & $33.33 \%-66.67 \%$ & $\geq 66.67 \%$ \\
\hline
\end{tabular}

\subsection{Overall Green Score of Data Center}

By using the metrics in each category, the final score for categories were created, this means that for calculating Reducing score, only metrics in the reducing box have been used and so on.

Finally, the overall score of data center was calculated by using the weights created in the previous chapter in table 3.2 . Therefore,

Overall Green Score of a Given Data Center $=$ PUE $\times 0.118+$ WUE $\times 0.059+$

(UPS + RCI (Hi) + RCI(Lo) + RTI + Airflow Efficiency + Humidity + ERE + MRR(Reuse) + GEC) $\times 0.071+\operatorname{MRR}($ Recycle $) \times 0.047$

\section{IMPLEMENTATION}

After designing the tool, the next step was building it on Microsoft Excel sheets. In building the dashboard, some similar tools were considered. 
The Green Data Center Virtual Dashboard consists of six sheets; Home, Energy Consumption, Cooling System, Material Tracking, Greenhouse Gas, and Dashboard.

The first sheet is "Home", which provides a brief explanation of the tool guidelines and forecasted outcomes. For ease of the users, four separate sheets were dedicated to each category of data. These sheets are Energy Consumption, Cooling System, Material Tracking, and Greenhouse Gas emissions. It should be noted that all the figures are for displaying purposes.

\section{CONCLUSION}

It can be seen that while normally a data center with excellent PUE is considered green, solely reducing aspects are not sufficient. While a data center operates green in terms of reducing energy and greenhouse gas emission, they still need to consider other aspects of 3Rs concept.

By using 3-color virtual dashboard, data center managers can gain a more comprehensive understanding of their facilities strengths and weaknesses, a big picture that does not only focus on reducing.

\section{RECOMMENDATIONS}

Every research has limitations; this study is not an exception. The obstacles of doing this study were gathering primary data, doing interviews an also insufficient work on this topic due to its novelty. One of the main obstacles was gaining participants' agreement, as they were either unwilling or busy scheduled during the research deadline; therefore, from a list of 10 possible candidates, finally only 2 accepted to be interviewed. Another limitation of this study was gaining primary data for testing the virtual dashboard. The fact that data centers in Cyberjaya were not willing to share their database was one of the main reasons. Although, those who were willing to cooperate did not have sufficient data; for example some data centers were not using water or did not track reusing of energy or material. Subsequently, secondary data were used for testing the virtual dashboard as well as performing a comparison between two cases. The next obstacle in accomplishment of this study was the metrics. All the metrics used in the final dashboard are from proposed metrics by researchers and organizations; however there is still need for more metrics especially on reusing and recycling aspect. Therefore, as the scope of this research did not include proposing new metrics, there is still a need for new and consistent metrics for tracking reusing of water, specific types of energy and recycling of water.

\section{Future Development and Studies}

There are vast possibilities of improving and developing the initial version, such as:

1. Enhancing tool's sensitivity by expanding the range of colors to 5 or more, which will provide more detailed sensitive results in comparison with the 3 -color version.

2. Implementing the tool as independent software: the final version of the dashboard in this study is implemented on Microsoft Excel Sheets. It is worthy to convert this dashboard into independent software, which would offer better user interface and can include extended options, such as reports.

3. Conversion of tool from software to hardware: creating a physical tool, which works separately, is another development option for this virtual dashboard. It is possible to create a hardware device, which works by using the software created for it.

4. Real-time results by direct installation of the tool in the data center infrastructure: one of the most interesting future possibilities for this dashboard is creating real-time connection between the dashboard and data center by providing on real-time data. This would result in $24 / 7$ monitoring of the whole data center infrastructure.

\section{REFERENCES}

[1] Apple. (2011). iCloud. Retrieved October 17, 2011, from Apple Inc.: www.apple.com

[2] Coroama, V., \& Hilty , L. M. (2009). Energy Consumed vs. Energy Saved by ICT - A Closer Look. Environmental Informatics \& Industrial Environmental Protection: COncepts, Methods \& Tools , 353-361.

[3] Daim, T., Justice, J., Krampits, M., Subramanian, G., Subramanian, G., \& Thirumalai, M. (2009). Data center metrics: An energy efficiency model for information technology managers. Management of Environmental Quality , 20 (6), 712-731.

[4] Davis, A. M., Bersoff, E. H., \& Comer, E. R. (1988). A Strategy for Comparing Alternative Software Development Life Cycle Models. 14 (10), 1453-1461.

[5] ENERGY STAR. (2012). Portfolio Manager Overview. Retrieved March 4, 2012, from ENERGY STAR: http://www.energystar.gov/index.cfm?c=evaluate_performance.bus_portfoliomanager

[6] EPA, The Green Grid \& Uptime Instittue. (2010). Recommendations for Measuring and Reporting Overall Data Center Efficiency. EPA, The Green Grid \& Uptime Instittue. EPA, The Green Grid \& Uptime Instittue. [online] available at:< http://www.eni.com/green-data-center/it_IT/static/pdf/Green_Grid_Recomm.pdf>[accessed on 10 Jan 2012]

[7] (GeSI), The Climate Group and Global eSustainability Initiative. (2008). SMART 2020: Enabling the low carbon economy in the information age. The Climate Group and Global eSustainability Initiative (GeSI). 
[8] Green Grid. (2007). Green Grid Metrics: Describing Datacenter Power Efficiency. [online] available at:< http://www.thegreengrid.org/ /media/WhitePapers/Green_Grid_Metrics_WP.pdf?lang=en> [accessed on 3 Dec 2011]

[9] Green Grid. (2011). Carbon Usage Effectiveness (CUE): A Green Grid Data Center Sustainability Metric . The Green grid. The Green Grid. [online] available at:< http://www.thegreengrid.org/ /media/WhitePapers/CarbonUsageEffectivenessWhitePaper20101202.ashx?lang= en> [accessed on 10 Feb 2012]

[10] Green Grid. (2011). Data Center Efficiency Metrics: mPUE ${ }^{\mathrm{TM}}$, Partial PUE, ERE, DCcE. Green Grid. Green Grid. [online] available http://www.thegreengrid.org/ /media/TechForumPresentations2011/Data_Center_Efficiency_Metrics_2011.pdf?| ang=en $>$ [accessed on 23 Jan 2012]

[11] Green Grid. (2011). WATER USAGE EFFECTIVENESS (WUETM): A GREEN GRID DATA CENTER SUSTAINABILITY METRIC. Green Grid. Green Grid.

[12] Green Grid. (2011). White Paper \#36: DATA CENTER MATURITY MODEL. Green Grid. Green Grid [online] available

at:< http://www.thegreengrid.org/ /media/WhitePapers/Data\%20Center\%20Maturity\%20Model\%20White\%20Paper_fi nal.ashx?lang=en $>$ [accessed on 17 Aug 2011]

[13] Lucente, E. J. (2010, june). The Coming ' $C$ ' Change in Datacenters. [online] available at:< http://www.hpcwire.com/hpcwire/2010-06-15/the_coming_c_change_in_datacenters.html> [accessed on 10 July 2011]

[14] Narayan, A. S. (2009). Power and Energy Management in Data Centers. ACM Surveys.

[15] PM Solutions. (2003). Selecting a Software Development Life Cycle (SDLC) Methodology A Practical Decision Framework to Maximize Business Value. Project Management Solutions, Inc. \& Park Hill Technologies LLC. Project Management Solutions, Inc. \& Park Hill Technologies LLC.

[16] Tomory, C. (2010). Lowering the Carbon Emissions Footprint of Enterprise Data Centers Through Energy Efficiency Gains. University of Oregon, Applied Information Management Program . Oregon: University of Oregon

[17] Yi, L., \& Thomas, H. R. (2007). A review of research on the environmental impact of e-business and ICT. Elsevier.

\section{Author' biography with Photo}

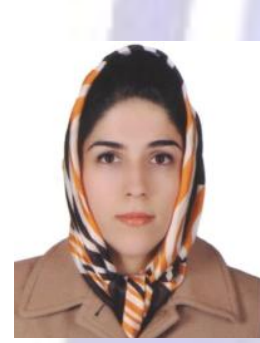

Fatemeh Binesh

Fatemeh (Nasim) Binesh born in Mashhad, Iran on $14^{\text {th }}$ March 1985. She got BSc. Statistics from Ferdowsi university of Mashhad. Later she applied for MBA program abroad to fulfill her passion. Meanwhile she was working as a lecturer in Payam Nour University. After acceptance, she moved to Malaysia and completed MBA in General Management courses in Multimedia University as a high achievement student, and currently is a PhD. Student at University Malaya, Malaysia. She has published several papers in international journals, and her latest published work is mathematics dictionary with collaboration with Payam Nour University of Mashhad, Iran. 